\title{
Elevated levels of tumour endothelial marker-8 in human breast cancer and its clinical significance
}

\author{
GAYNOR DAVIES $^{1}$, KHALED A. RMALI ${ }^{1}$, GARETH WATKINS ${ }^{1}$, ROBERT E. MANSEL ${ }^{1}$, \\ MALCOLM D. MASON ${ }^{2}$ and WEN G. JIANG ${ }^{1}$ \\ ${ }^{1}$ Metastasis \& Angiogenesis Research Group, Department of Surgery, Wales College of Medicine, \\ Cardiff University, Heath Park, Cardiff, CF14 4XN; ${ }^{2}$ Department of Clinical Oncology, \\ Velindre Hospital, Cardiff, CF4 7XL, UK
}

Received April 14, 2006; Accepted June 13, 2006

\begin{abstract}
Tumour endothelial marker-8 (TEM-8) belongs to a family of endothelial markers that are raised during tumour angiogenesis. We have recently reported aberrant expression of TEMs at the mRNA level in human breast cancer. This study sought to examine the level of TEM-8 expression at the protein and mRNA level in human breast cancer tissue, and in a panel of human breast cancer cell lines. We also wished to determine if TEM- 8 can be used as a suitable marker for identifying tumour associated micro-vessels. At the mRNA level more tumours showed positive TEM-8 expression compared to normal background tissue. TEM- 8 was detected in a variety of breast cancer cell lines, endothelial cells (HECV) and in a human fibroblast cell line (MRC5) at both the mRNA and protein level. Using immunohistochemistry the distribution of TEM-8 staining was more widespread in invasive breast cancer tissue compared to normal background tissue. Furthermore, the TEM- 8 marker was found to be more discriminatory in identifying micro-vessels in tumour endothelium $(2.8 \pm 0.83$ vs. normal $1.66 \pm 0.52 ; \mathrm{P}<0.011)$, compared to the vWFA marker $(1.61 \pm 0.54$ vs. normal 2.71 $\pm 0.76 ; \mathrm{P}<0.009)$. Raised levels of TEM-8 were associated with shorter survival outcome, but were not correlated to disease-free survival as shown by Kaplan-Meier and Cox regression analysis. We conclude that TEM-8 is a useful marker for identifying tumour associated
\end{abstract}

Correspondence to: Professor Wen G. Jiang, Metastasis \& Angiogenesis Research Group, University Department of Surgery, Wales College of Medicine, Cardiff University, Heath Park, Cardiff, CF14 4XN, UK

E-mail: jiangw@cf.ac.uk

Abbreviations: ATR, anthrax toxin receptor; cDNA, complementary deoxyribonucleic acid; EF, edema factor; LF, lethal factor; LeTx, lethal toxin; mRNA, messenger ribonucleic acid; PCR, polymerase chain reaction; Q-RT-PCR, quantitative real-time polymerase chain reaction; RNA, ribonucleic acid; TEM-8, tumour endothelial marker-8

Key words: angiogenesis, TEM-8, breast cancer micro-vessels and that elevated levels are associated with disease progression, which may have some bearing on the prognostic outcome in breast cancer.

\section{Introduction}

Tumour endothelial marker-8 (TEM-8) belongs to a family of TEMs that were identified by St. Croix et al (1) as genes predominantly expressed in tumour endothelium. This group demonstrated that mRNA from TEMs including TEM-8 was preferentially expressed in endothelial cells derived from malignant colorectal tissue. In a follow-up study it was revealed that TEM-8 was readily detected in mouse endothelium associated with both developmental angiogenesis and tumour angiogenesis (2). TEM-8 has been shown to function as a cell surface tumour endothelial marker that is highly conserved in both mice and human tumour endothelium, thus making TEM-8 an attractive marker for the establishment of an in vivo model system in an attempt to assess anti-angiogenic strategies in combating tumour growth. Interestingly, the TEM- 8 gene has been identified to encode the anthrax toxin receptor (ATR) (3). This receptor also has a related protein encoded by the capillary morphogenesis gene 2 (CMG2) and this shares a high degree of amino acid identity in the $\alpha$-integrin-like inserted domain (I-domain or von Willebrand factor type A domain), as well as a conserved metal ion dependent adhesion site (MIDAS) motif $(4,5)$. The identification of the ATR/TEM-8 cell surface receptor has generated much excitement for targeting tumour angiogenesis as a potential therapeutic approach for treating cancer (6).

The presence of the ATR/TEM8 receptor on the cell surface indicates that this protein may have additional roles to play such as cellular adhesion, besides its role in mediating angiogenesis (6). Recently, St. Croix's group have raised an anti-TEM-8 antibody to the extracellular domain of TEM-8 and shown it to associate with a cleaved C5 domain of collagen $\alpha 3$ (V1), thus indicating a role in cellular adhesion as well as tumour angiogenesis (7). Furthermore, we have recently shown TEM- 8 to be up-regulated at the mRNA and protein level in endothelial cells after stimulation by interleukin-1ß (IL-1ß), thus indicating a possible pathway in the regulation of tumour associated angiogenesis by IL-1ß 
(8). To target tumour angiogenesis and intoxicate cancer cells a polypeptide component of the anthrax toxin known as protective antigen (PA) binds to the ATR/TEM-8 cell surface receptor and undergoes cleavage by a cellular furin-like enzyme, to allow for the subsequent binding of either edema factor $(E F)$, or lethal factor (LF) toxins $(9,10)$. Targeting the anthrax toxin receptor with anthrax lethal toxin (LeTx) has proved promising as a potential anti-cancer therapy by inhibiting both tumour growth and angiogenesis in a mouse model (11). We have previously shown TEM-8 to be an attractive marker for assessing the degree of tumour angiogenesis in a nude mouse prostate model (12). This endothelial marker was found to be more tumour-specific in experimental mouse tumours, whereas TEM-1 levels were detected in a variety of normal mouse tissue including skin, subcutaneous tissue, heart and skeletal muscle. More recently, using a cohort of breast tissue with a 6-year follow-up, we found that elevated levels of TEM-1, TEM-7R and TEM-8 (but not TEM-2, 4, 5, 6 and 7) had a clinical bearing in breast cancer as they were associated with either nodal involvement, and/or disease progression (13). However, this study also demonstrated that TEMs were expressed in both normal and tumour tissues, which is conflicting with earlier reports stating that their levels in normal tissue were low, or virtually undetected $(1,2)$. Furthermore, the same group identified expression of TEMs during developmental angiogenesis of the corpus luteum and wound healing (2), suggesting that it may play a transient role in these processes.

This study raised a few questions that need to be addressed. Firstly, are factors that switch on TEM expression released into the same breast tissue adjacent to the tumour (hence background tissue) that consequently renders low level expression? Secondly, TEMs may not be highly specific to endothelial cells and some other cell types may also express these markers. In an attempt to answer these questions, we previously raised an anti-TEM-8 [referred to as TEM-8 (hm) in the text] antibody (8) and compared its specificity to a commercially available anti-TEM-8 [referred to TEM-8 (sc) in the text] antibody to test the level of this protein in breast cancer. In the current study we wished to test whether this elevated level of TEM-8 expression was preserved at the protein level in breast cancer and whether its level was specific to endothelial cells. To test this hypothesis we screened breast cancer tissue with an extended follow-up (10 years), breast cancer cell lines, endothelial cells and fibroblast cells.

\section{Materials and methods}

Materials. Peroxidase-conjugated secondary antibodies to mouse and rabbit were obtained from Sigma (Poole, Dorset, UK). Mouse monoclonal anti-actin and rabbit polyclonal antivWFA (von Willebrand factor A) were obtained from Santa Cruz Biotechnology, Inc. (Santa Cruz, CA). Rabbit polyclonal anti-ART/TEM-8 was obtained from Santa Cruz (Santa Cruz, CA). The KPL chemiluminescence kit was purchased from Insight Biotechnology (Wembley, Middlesex, UK). All other reagents were obtained from Sigma unless otherwise stated.

Cell culture conditions. Human breast cancer cell lines MDA435S, MDA453 and MDA436 were purchased from
Cancer Research UK (London, UK). The human fibroblast cell line MRC5, and human breast cancer cell lines MCF7, MDA-MB-231 and ZR751 were purchased from the ECACC (European Collection of Animal Cell Cultures, Salisbury, UK). The human endothelial cell line HECV was obtained from Interlab Cell Line Collection (ICLC, Naples, Italy). Cell lines were routinely maintained in F12 medium (Cambrex Bio Science, Verviers, Belgium) supplemented with $10 \%$ fetal calf serum (PAA Laboratories, Yeovil, UK) and antibiotics.

Collection and storage of breast tissues. Frozen breast cancer tissue $(n=120)$ together with 33 normal background tissues with a median follow-up of 120 months were collected immediately after mastectomy, and stored at $-80^{\circ} \mathrm{C}$ until ready for use (collected with approval of local ethical committees). A pathologist verified normal background and cancer tissues, and confirmed that background tissues were free from tumour deposits.

Generation and purification of anti-TEM-8 antibody. This procedure was based on our previously published method (8). Briefly, a 15 amino acid peptide matching the $\mathrm{N}$-terminus of human TEM-8 was synthesised (Sigma-Genosys, Cambridgeshire, UK), purified, conjugated to Hemocyanin (KLH; Sigma) and injected into rabbits with complete Freund's adjuvant (Sigma) solution according to a standard protocol (14). Anti-sera were obtained after a series of injections and booster injections. Before the immunoglobulin was purified from anti-sera using a protein-A sepharose affinity column (Sigma), we first removed the lipid content by delipidation using 1, 1, 2-trichloro-trifluoroethane in a solvent/serum ratio of $3: 2$. The mixture underwent agitation for $30 \mathrm{~min}$, centrifiguation at $5000 \mathrm{rpm}$ for $10 \mathrm{~min}$ and the top layer was aspirated for purification. Delipidated antisera was diluted with $10 \mathrm{mM}$ PBS (phosphate-buffered saline at $\mathrm{pH} 7.4$; Sigma) solution at a 1:1 ratio and loaded onto the sepharose column (previously equilibrated with $10 \mathrm{ml}$ of PBS solution). The column was then washed with $7 \mathrm{ml}$ of PBS solution. Bound antibody was eluted from the column using $5 \mathrm{ml}$ of elution buffer (0.1 M Glycine-HCl at $\mathrm{pH} 2.7)$. Fractions (1 ml) were collected in tubes containing $100 \mu 1$ of neutralisation buffer (1 M Tris- $\mathrm{HCl}, 4.2 \% \mathrm{HCl}$ at $\mathrm{pH} 8.0)$ and immediately mixed. Purified TEM- 8 antibody was then preserved in glycerol at a $1: 1$ ratio and stored at $-20^{\circ} \mathrm{C}$ until required.

The specificity of the antibody was verified using the TEM-8 peptide and other synthetic peptides irrelevant to TEM-8, as well as cell lysates using a slot blot according to our recent publication (8).

RT-PCR for TEM-8 detection in breast cancer. Total cellular RNA was isolated from either homogenised breast tissues, or cell line monolayers using RNA-Zol reagent (ABgene, Epsom, UK) according to the manufacturer's instructions. cDNA was generated from $1 \mu \mathrm{g}$ RNA using an AMV-reverse transcription kit (ABgene, Epsom, Surrey, UK). PCR was carried out using the following primer pairs (Gibco BRL, Life Technologies, Inc., Paisley, Scotland, UK): TEM-8F2 (5'-catttcaagttgtcgtgaga) and TEM-8R2 (5'-gacgcatattgttgttg aga to amplify human TEM-8); ß-ACTF (5'-atgatatcgccgcgc tcg) and B-ACTR (5'-cgctcggtgaggatctcca to amplify human 
B-actin). PCR reactions were performed using a GeneAmp PCR system 9700 (PE Biosystems, Warrington, UK) thermal cycler. Amplification of cDNA samples was carried out under the following conditions: $94^{\circ} \mathrm{C}$ for $5 \mathrm{~min} ; 36$ cycles at $94^{\circ} \mathrm{C}$ for $30 \mathrm{sec}, 54^{\circ} \mathrm{C}$ for $40 \mathrm{sec}$, and $72^{\circ} \mathrm{C}$ for $50 \mathrm{sec}$; followed by $72^{\circ} \mathrm{C}$ for $7 \mathrm{~min}$. The PCR products, including a $1-\mathrm{kb}$ ladder were separated on $0.8 \%$ agarose gels. PCR products were then visualised using ethidium bromide $(10 \mathrm{mg} / \mathrm{ml})$ and a UV transilluminator (UVItec, Cambridge, UK). Agarose gels were photographed using a Unisave camera (Wolf Laboratories) and subsequent images documented using Adobe Photoshop Elements software.

Quantitative real-time PCR analysis of TEM-8 in breast cancer. The levels of TEM-8 transcripts were assessed from cDNA generated from breast tissue according to our previously published method (12). Briefly, an Amplifor Unifluor probe detection system (Intergen, Oxford, UK) and a 2x Hot start QPCR master mix were used according to the manufacturer's instructions $\left(\mathrm{ABgene}^{\circledR}\right)(15,16)$. QPCR was carried out using the following primers (Gibco BRL, Life Technologies, Inc.); TEM8ZF1 (5'-acagggtcctctgcagctt) and TEM8ZR1 5'-[5'actgaacctgaccgtacactttcatgccaacttgttt (the underlined part of the primer is the z-sequence for Q-RT-PCR) to amplify human TEM-8]. Plasmid templates with known copy numbers were prepared previously using a plasmid/E. coli vector (Topo TA cloning, Invitrogen, Paisley, UK) cloning kit according to the manufacturer's instructions (Invitrogen), and used to calculate the number of transcripts in unknown samples. Quantitation was carried on an iCycler-iQ ${ }^{\mathrm{TM}}$ system (Bio-Rad, Surrey, UK), which incorporated a gradient 96 module, an optical unit, and a four-dye detection system. Reactions were carried out under the following conditions: $95^{\circ} \mathrm{C}$ for $12 \mathrm{~min}$; 56 cycles at $95^{\circ} \mathrm{C}$ for $15 \mathrm{sec}, 55^{\circ} \mathrm{C}$ for $50 \mathrm{sec}$; followed by $72^{\circ} \mathrm{C}$ for $20 \mathrm{sec}(12,15)$. Copy numbers for TEM-8 expression in the unknown samples were determined from the standard curve generated by the QPCR run.

Immunohistochemical detection of TEM-8 in breast cancer. This procedure was based on our previously published method with minor modifications (17). Briefly, frozen sections of breast tumour and normal background tissues were cut to a thickness of 6- $\mu \mathrm{m}$ using a cryostat. The sections were mounted on super frost plus microscope slides, air-dried and then fixed in a mixture of $50 \%$ acetone and $50 \%$ methanol. Cut sections were washed in Optimax (diluted according to the manufacturer's instructions) wash buffer (Bio-Genex, San Ramon, California, USA) for 5-10 min to rehydrate tissues. Sections were incubated for $20 \mathrm{~min}$ in a horse-serum (Vectastain, ABC Universal Kit, Nottingham, UK) blocking solution and probed with either anti-TEM-8 (hm; 1:40), antiTEM-8 (sc; $1: 100)$ or anti-vWFA (1:100) primary antibodies for $1 \mathrm{~h}$ and washed four times in Optimax wash buffer. Bound antibody was detected using a biotinylated (diluted according to the manufacturer's instructions) secondary antibody (Biotinylated pan specific (BA-1300), Vector Laboratories, Nottingham, UK) for $30 \mathrm{~min}$ and washed extensively in Optimax wash buffer. Sections were then incubated with an avidin biotin (Vectastain) complex (diluted according to the manufacturer's instructions) label for $30 \mathrm{~min}$, followed by extensive washing. Diamino benzidine chromogen (Vectastain) supplemented with $\mathrm{H}_{2} \mathrm{O}_{2}$ (diluted according to the manufacturer's instructions) was then added to the sections and incubated in the dark for $5 \mathrm{~min}$. Cut sections were then stained in Gill's Haematoxylin for $1 \mathrm{~min}$, washed in tap water for $5 \mathrm{~min}$ and dehydrated in ascending grades of methanol before clearing in xylene and mounting under a cover slip. Mounted (DPX mounting reagent) sections were then screened using a light microscope (Olympus, BH2) and images were obtained from a digital camera.

Micro-vessel counts were carried out by an independent examiner using the following criteria. Dark brown granules in interstitial spaces demonstrated TEM- 8 and vWFA positive staining. The staining was excluded from the analysis if it was located on the cell surface and lumen staining was not necessary for positive identification of a micro-vessel. At least five non-overlapping fields were screened after locating and identifying a definite micro-vessel within the stromal tissue with which to compare staining intensity. The screening procedure was based on our previously published method $(18,19)$.

Western blot analysis of TEM-8 from crude cell lysate. Cells were detached using a cell scraper, pelleted at 2,000 x g for $2 \mathrm{~min}$ and lysed in lysis buffer $(75 \mathrm{mM} \mathrm{NaCl}, 25 \mathrm{mM}$ Tris- $\mathrm{HCl}, 0.01 \%$ sodium azide, $0.25 \%$ sodium deoxycholate, $10 \mathrm{mM} \mathrm{Na} \mathrm{VO}_{4}, 10 \mathrm{U} / \mathrm{ml}$ aprotinin, $1 \mathrm{mM}$ phenylmethylsulfonyl fluoride, $1.5 \%$ Triton $\mathrm{X}-100$ ) for $40 \mathrm{~min}$ at $4^{\circ} \mathrm{C}$. Cell lysates from each sample were extracted by centrifugation at $13,000 \mathrm{x} g$ for $15 \mathrm{~min}$. Protein concentrations were measured using fluorescamine (Sigma) and quantified by using a microplate flouorescent reader (Denley, Sussex, UK). The protein samples were then diluted with sample buffer (2\% SDS, $10 \%$ glycerol, $0.002 \%$ bromophenol blue, $0.0625 \mathrm{M}$ Tris- $\mathrm{HCl}$ and $5 \%$ 2-mercaptoethanol at $\mathrm{pH}$ 6.8) to yield a concentration of $1 \mathrm{mg} / \mathrm{ml}$ and boiled at $100^{\circ} \mathrm{C}$ for $5 \mathrm{~min}$ under reducing conditions. Equal amounts ( $10 \mu \mathrm{g} /$ well) of protein from each sample were then loaded onto a $10 \%$ polyacrylamide gel. Nitrocellulose membranes were probed with either an antiTEM-8 (hm; 1:60), anti-TEM-8 (sc; 1:200) or an anti-actin (1:400) primary antibody for $1 \mathrm{~h}$ and subsequently labelled using appropriate horseradish peroxidase-conjugated (HRPconjugated) secondary (1:1500) antibodies (Sigma) for $1 \mathrm{~h}$. Protein bands were visualised using an enhanced KPL chemiluminescence kit.

\section{Results}

TEM-8 mRNA levels are elevated in breast cancer. The level of TEM- 8 was assessed at the mRNA level using 7 paired breast samples as part of our pilot study. Fig. 1 (top) shows the RT-PCR data for the level of endogenous TEM-8 expression detected in normal background tissue and breast cancer tissue respectively. We found the level of TEM- 8 to be significantly $\left(\mathrm{P}<0.05 ; \chi^{2}\right.$ test) higher in breast cancer tissue with 6/7 (86\%) of the paired breast samples expressing the TEM- 8 transcript. In contrast, the level of TEM-8 expression was much lower in normal background tissue with $2 / 7$ (29\%) of the paired breast samples expressing TEM- 8 at the mRNA level, thus 


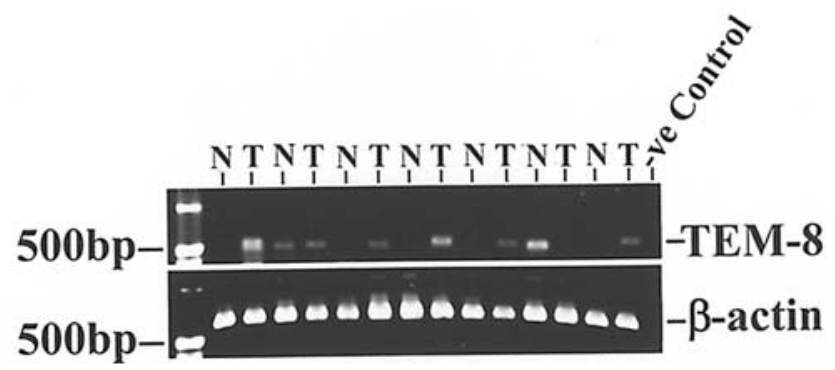

Figure 1. The detection of TEM-8 (top) in normal background breast tissue and breast cancer tissue respectively in 7 matched samples using RT-PCR. Breast cancer tissue expressed a higher level of TEM- 8 at the mRNA level compared to normal background tissue. $\beta$-actin was found to be present in all samples (bottom).

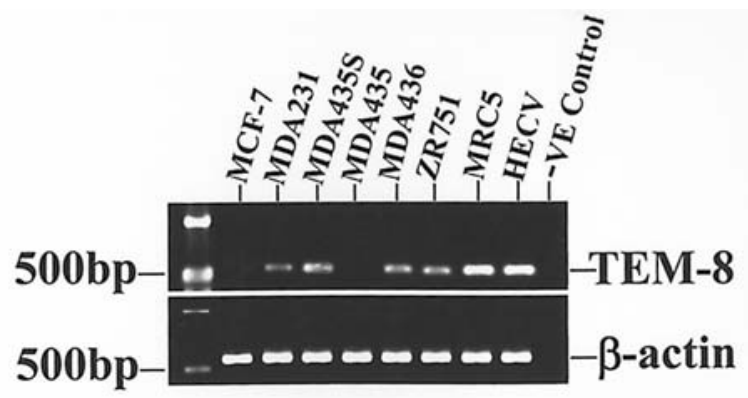

Figure 2. The detection of the TEM-8 transcript (top) in a panel of human breast cancer cell lines, an endothelial cell line HECV and a fibroblast cell line MRC5 using RT-PCR. High levels of TEM-8 expression were detected in HECV and MRC5 cells, with varying levels of expression detected in breast cancer cells. The bottom panel refers to the level of normalised control $\beta$-actin.

indicating that TEM-8 may not be tumour endothelial specific. To determine if TEM- 8 is indeed endothelial specific we screened a panel of six breast cancer cell lines, an endothelial cell line and a fibroblast cell line to examine its presence at the mRNA level. Fig. 2 (top) shows that TEM- 8 was as expected detected in the endothelial cell line HECV. Interestingly, the TEM-8 transcripts were detected in the fibroblast cell line MRC5, and the breast cancer cell lines MDA231, MDA435S, MDA436 and ZR751. There was no TEM-8 transcript detected in either MCF7 or MDA453 breast cancer cell lines.

Elevated levels of TEM-8 are associated with shorter survival in breast cancer. We have previously shown the level of TEM- 8 to be elevated in a cohort of 120 breast cancer tissues compared to normal background tissue $(n=33)$ at the mRNA level (13). In the current study we wanted to verify if elevated TEM-8 levels correlated to the number of patients who had died from breast cancer. We looked at the level of TEM-8 expression from QPCR data in this group of patients using Kaplin-Meier and Cox-regression analysis (SPSS, version 11) as shown in Fig. 3. TEM-8 levels $>1$ were considered to be high. The cumulative survival plotted from this data suggested that patients who had high levels of TEM- 8 had a shorter survival [median 122 months (94.2-149.8)] compared to those who had low (i.e. <1) TEM-8 levels $[134.8$ months (124.9-144.8)]. However, this trend was not statistically significant $(\mathrm{P}=0.28)$. When the disease-free survival data was analysed high [median 118.8 months (108.8-129.3)]

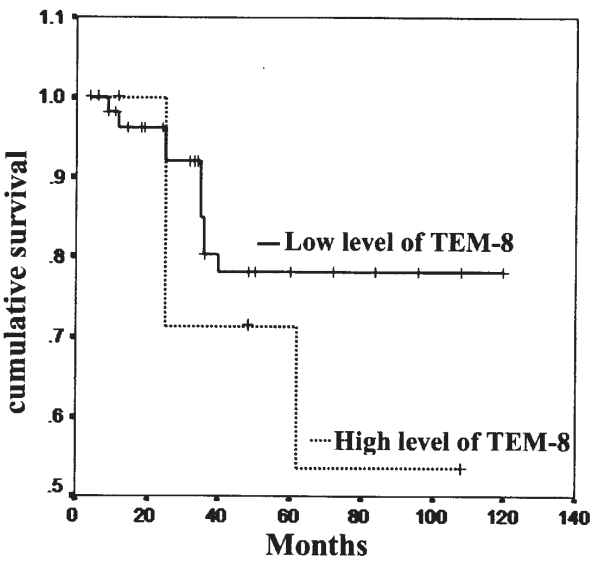

Figure 3. The cumulative overall survival generated using Kaplin-Meier and Cox-regression analysis (SPSS, version 11). Patients who had a high level of TEM-8 in tumour tissues had a shorter survival, compared to those who had a lower level of expression. However, this trend was not statistically significant $(\mathrm{P}=0.28)$.

levels of TEM- 8 were not significantly $(\mathrm{P}=0.68)$ correlated to low [131.5 months (109.6-153.3)] TEM-8 levels.

TEM-8 protein levels are elevated in breast cancer with increased vascularisation. To determine if elevated levels of TEM-8 expression were preserved at the protein level in tumour endothelium, we used both anti-TEM- 8 antibodies and compared the level of endothelial staining to an antivWFA antibody on invasive breast cancer tissue and normal background tissue as shown in Fig. 4. In normal background tissue there were strong levels of vWFA staining (top panel, left hand side) in endothelial cells lining vessels compared to the weak levels of staining detected in TEM-8 sections (top panel, middle and right hand side). In contrast, breast tumour tissue had strong levels of TEM-8 staining in endothelial cells lining vessels with moderate staining of cancer cells (bottom panel, middle and right hand side). In addition, both TEM-8 antibodies were found to stain stromal and epithelial cells in breast tissues. vWFA staining in breast tumours (bottom panel, left hand side) was strongly expressed in endothelial cells lining vessels; however, there was more vascularisation detected and, again, there was moderate staining of cancer cells.

We also counted the number of micro-vessels formed in normal and breast cancer tissues to verify that the TEM- 8 marker is more specific than the vWF marker for identifying tumour endothelial angiogenesis according to our previously published method (18). In Table I significantly more microvessels were identified in breast tumour tissue by both TEM-8 antibodies and to a similar degree, compared to normal breast tissue (mean $2.8 \pm 0.83$ positive vessels counted in tumour tissue for anti-TEM-8 (hm) vs. $1.66 \pm$ SD 0.52 in normal background tissue; $\mathrm{P}=0.011$ ) and (mean $2.6 \pm 0.89$ positive vessels counted in tumour tissue for anti-TEM-8 (sc) vs. $1.83 \pm \mathrm{SD} 0.41$ in normal background tissue; $\mathrm{P}=0.045$ ) respectively. In contrast, the vWFA marker identified significantly less micro-vessels in breast tumour tissue compared to normal background tissue (mean 1.61 \pm SD 0.54 positive vessels counted in tumour tissue vs. $2.71 \pm \mathrm{SD} 0.76$ in normal background tissue; $\mathrm{P}=0.009$ ), thus indicating that TEM-8 is a superior marker than vWFA for assessing tumour associated micro-vessels in breast cancer. 


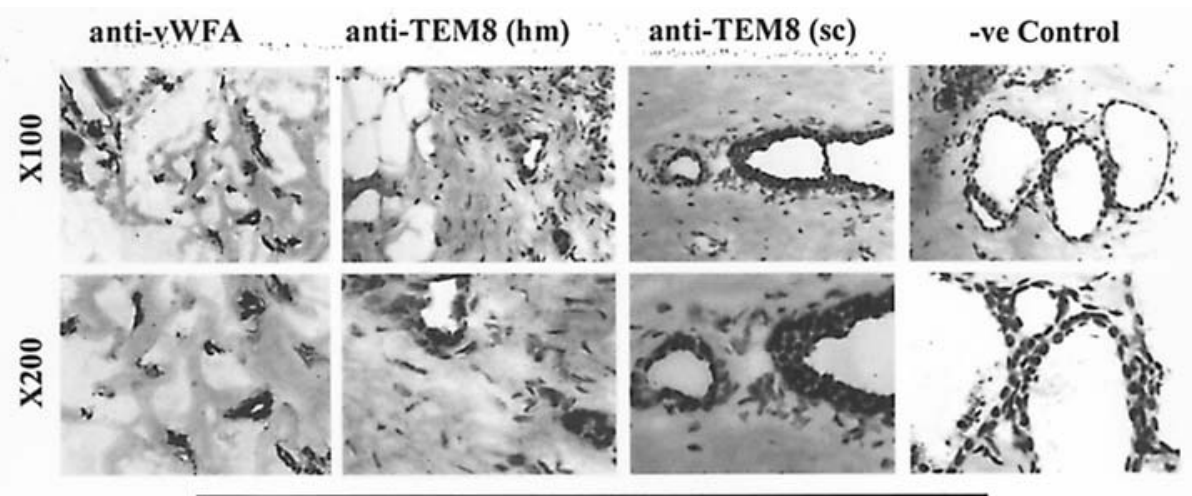

Normal mammary tissue

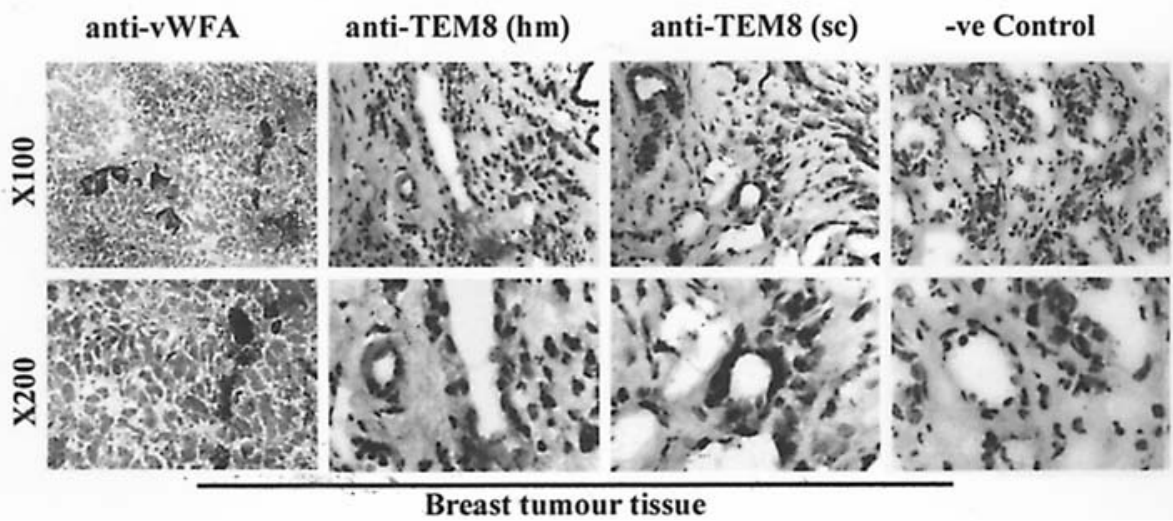

Figure 4. Immunohistochemical staining of TEM-8 (middle and right hand side panels) and vWFA (left hand side panels) in normal background tissue (top panels), and invasive breast cancer tissue (bottom panels). There was a higher level of TEM-8 staining in invasive breast cancer tissue compared to those stained using vWFA.

Table I. Micro-vessel counts

\begin{tabular}{lccc}
\hline & $\begin{array}{c}\text { No. of } \\
\text { vWFA } \\
\text { positive } \\
\text { vessels }\end{array}$ & $\begin{array}{c}\text { No. of } \\
\text { TEM-8 (hm) } \\
\text { positive } \\
\text { vessels }\end{array}$ & $\begin{array}{c}\text { No. of } \\
\text { TEM-8 (sc) } \\
\text { positive } \\
\text { vessels }\end{array}$ \\
\hline $\begin{array}{l}\text { Normal breast } \\
\text { tissue }\end{array}$ & $2.71 \pm 0.76$ & $1.66 \pm 0.52$ & $1.83 \pm 0.41$ \\
$\begin{array}{l}\text { Cancer breast } \\
\text { tissue }\end{array}$ & $1.61 \pm 0.54$ & $2.8 \pm 0.83$ & $2.6 \pm 0.89$ \\
P-values & 0.009 & 0.011 & 0.045 \\
\hline
\end{tabular}

The number of micro-vessels counted from immunohistochemical stained sections using either an anti-vWFA or an anti-TEM-8 antibody in normal and tumour breast tissues. Values are mean $\pm \mathrm{SD}$ and P-values as determined by Student's t-test.

Breast tissues are composed of a heterogeneous population of cell types including epithelial, endothelial and stromal cells which have all stained positively for TEM- 8 expression in this study; we wanted to test if this protein was truly present in homogeneous cell populations and not just detected in heterogeneous cell populations from breast tissues as a result of factors that may switch on its expression. To test this

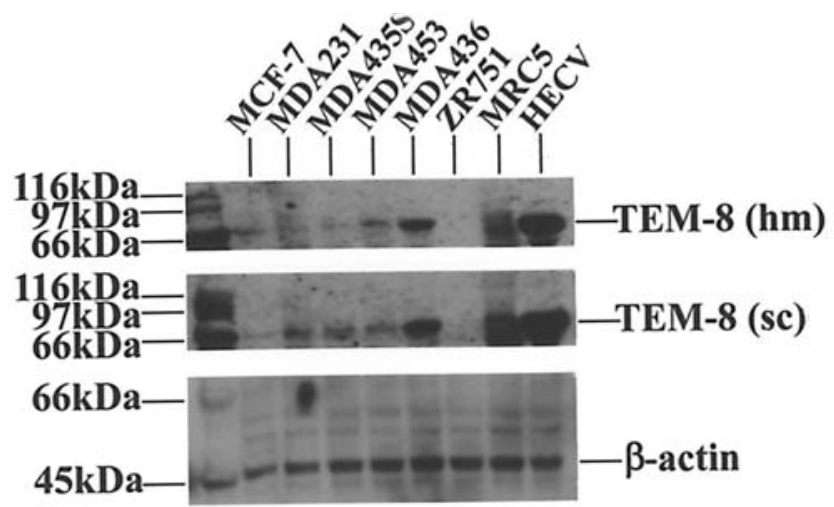

Figure 5. Protein profiles for TEM- 8 expression (top and middle panels) in a panel of human breast cancer cell lines, a fibroblast cell line and an endothelial cell line. A high level of TEM- 8 was detected in HECV cells. TEM- 8 was also expressed in the fibroblast cell line and in breast cancer cell lines. B-actin (bottom) was used as a normalised control and was found to be present in all samples.

hypothesis we screened a panel of epithelial breast cancer cell lines, an endothelial cell line and a fibroblast cell line. Fig. 5 (top and middle panels) shows the Western blot data for TEM-8 expression using both anti-TEM-8 antibodies. High levels of TEM- 8 protein were as excepted, detected in the endothelial cell line HECV. Interestingly, TEM-8 expression was detected in the fibroblast cell line MRC5, with varying levels of protein expression detected in 5 (MCF7, MDA231, MDA435S, MDA453, MDA436) of the breast cancer cell 
lines. Both anti-TEM- 8 antibodies were found to be virtually identical in their specificity for detection of TEM- 8 protein in the panel of cell lines screened.

\section{Discussion}

Angiogenesis plays a key role in cancer development including breast cancer progression, as this biological process provides all the necessary requirements for sustained growth via the establishment of an independent blood supply, consequently providing a direct route of entry into the bloodstream for the dissemination of tumour cells to form secondary foci (20). Since tumour growth is dependent upon angiogenesis for its continued survival, the application of anti-angiogenic therapies for targeting tumour growth have previously proved to be attractive approaches in the advancement for treating cancer metastasis (21-23). TEMs, including TEM-8, have been shown to be novel markers for assessing the degree of tumour angiogenesis, as their levels of expression are up-regulated during angiogenesis in tumour endothelial cells from colon tissue, while their levels in normal tissue have been either low or virtually undetected $(1,2)$.

We have recently demonstrated that TEM- 8 is a more reliable marker than $\mathrm{VWFA}$ for assessing the degree of micro-vessel density (MVD) in colon tumours (18). In this study, the MVD index was significantly elevated for TEM-8 expression in colon tumours compared to normal background tissues, whereas, vWFA was less discriminatory for MVD formation in tumour and normal endothelial cells. Furthermore, TEM-8 mRNA expression was significantly elevated in patients with advanced colon tumours using Dukes staging (i.e. Dukes $\mathrm{C}$ vs. Dukes $\mathrm{A} ; \mathrm{P}=0.01$ ), thus indicating that raised levels of TEM-8 are associated with disease progression in colon cancer (18). In the current study, we found TEM-8 to be a more superior endothelial marker than wVFA for identifying more positive vessels in breast tumour tissues compared to normal background tissues. This observation clearly strengthens our case that the TEM- 8 marker is able to clearly discriminate between micro-vessel formations in tumour endothelium that is specific to tumour angiogenesis, whereas, the vWFA marker failed to reveal an abundance of microvessels in tumour endothelium. This result is corroborated by our previous study on colorectal cancer where the TEM- 8 marker identified more tumour vascularisation in tumour endothelium compared to the vWFA marker (18). We have already highlighted that factors that are generated by breast tumour, or stroma cells may leak into adjacent normal breast tissue and switch on TEM expression in this region. In fact, we have previously reported that IL- $1 \beta$ up-regulates TEM- 8 expression in endothelial cells (8). Furthermore, studies have previously shown that stimulation by IL-1ß contributes to vascular endothelial cell growth factor, and tumour necrosis factor production in co-culture experiments between peritoneal macrophages and tumour cells (24-26).

This is the first study to our knowledge to show the expression of TEM-8 at the protein level in invasive breast cancer and normal background tissues respectively. We have previously shown TEMs (TEM-1, TEM-7R and TEM-8) to be elevated in a cohort of 120 breast cancer tissues compared to normal background tissue $(n=33)$ at the mRNA level only, and demonstrated that raised levels of TEMs were associated with either nodal involvement and/or disease progression (13). However, this study was limited in its scope because there was no antibody commercially available at the time to assess the preservation of these proteins. Consequently we raised our own antibody in-house against TEM- 8 as we have previously shown this marker to be superior (compared to TEM-1) for assessing the degree of tumour angiogenesis in a prostate nude mouse model (12). In the present study, we wished to evaluate a number of points raised in our previous breast cancer study (13): firstly, that we had detected TEM transcripts at a lower level in background tissue that lies adjacent to breast tumour tissue, we hypothesised at the time that factors that switch on TEM expression within breast tumour tissue diffuse into the surrounding tissue (i.e. background tissue) and thus render low level expression in background tissue; and secondly, that TEMs are not highly specific to endothelial cells and some other cell types may also express them as previously reported (12). In the current study, TEM-8 expression was significantly higher at the mRNA level (Fig. 1) in breast cancer tissue; present in $86 \%$ of the matched pairs tested compared with lower levels of detection in $29 \%$ of normal background tissue. This level of expression for TEM-8 was also present at the protein level (Fig. 4 bottom panel, middle and right) with higher levels detected in breast cancer tissue than in background tissue.

Both anti-TEM-8 antibodies used here worked equally well in identifying a similar number of micro-vessel densities in breast tissues $(1.66 \pm 0.52$ TEM-8 (hm) vs. $1.83 \pm 0.41$ TEM-8 (sc) for normal background tissue; $\mathrm{P}=0.275)$ and $(2.8 \pm 0.83$ TEM-8 (hm) vs. 2.6 \pm 0.89 TEM-8 (sc) for breast cancer tissue; $\mathrm{P}=0.362$ ) respectively. Interestingly, we found that there was strong staining of TEM-8 in epithelial, endothelial and stromal breast tissues as assessed by immunohistochemical staining which may help explain why low levels of TEM's are also detected in background tissue and are not entirely confined to the endothelial cells as previously thought (1). More recently, ATR/TEM-8 expression has been identified at the protein level in epithelial cells lining organs (i.e. lung skin and intestine) that offer three major routes of entry by anthrax toxin (27). Furthermore, the number of anthrax toxin receptors present in epithelial cells lining the lung, skin and intestine determines the organs increased sensitivity to infection by the anthrax toxin.

In the present study, we also screened a panel of 6 breast cancer cell lines, an endothelial cell line (HECV) and a fibroblast cell line (MRC5) to examine the expression profiles for TEM- 8 at the mRNA and protein level. High levels of TEM-8 were detected at the mRNA (Fig. 2) and protein (Fig. 5) level in endothelial cells (HECV). TEM-8 mRNA and protein expression was also detected in the fibroblast cell line MRC5 and breast cancer cell lines. Both antibodies used to assess the level of TEM- 8 protein gave virtually identical results in the panel of cell lines used (Fig. 5, top and middle panels). There are currently three isoforms of ATR/TEM- 8 that have been identified as a result of alternative mRNA splicing (27-29). The long isoform is thought to be glycosylated producing an approximate $80-85 \mathrm{kDa}$ doublet. The medium isoform is approximately a $60-\mathrm{kDa}$ protein and the short isoform is predicted to be $45 \mathrm{kDa}$. Only the long and medium 
spliced variants of ATR/TEM-8 have been reported to function as anthrax toxin receptors. The short isoform is a secreted protein product that does not act as a receptor for anthrax toxin. Bonuccelli and colleagues (27) recently raised an antiTEM-8 antibody that identifies all three spliced variants of the anthrax toxin receptor. They reported that ATR/TEM- 8 isoforms are tissue specific for example, the long isoform is predominantly expressed in lung and intestine, the medium isoform is highly expressed in intestine and liver, while the short isoform is expressed in skin. In the present study our raised antibody for TEM- 8 and the commercially available antibody identify the medium isoform in endothelial, fibroblast and epithelial cells, and its size is consistent to that in our previously published article (18).

We have demonstrated that elevated levels of TEM- 8 are correlated to a shorter survival in breast cancer as shown by Kaplin-Meier and Cox regression analysis survival curves (Fig. 3). Patients with recurrent disease, or who subsequently died from breast cancer had higher TEM-8 levels compared to those who remained disease-free. Although the current study failed to yield a statistical significance, which was partly due to the small sample size, a larger number of patients included in the study would certainly assist to address this point in the future. We conclude that raised levels of TEM- 8 are associated with disease progression in breast cancer and may have some clinical bearing in survival outcome.

\section{Acknowledgements}

We wish to thank Cancer Research Wales and Breast Cancer Campaign for funding this work. We are also indebted to Dr A. Douglas-Jones, Department of Pathology for his expert opinion.

\section{References}

1. St Croix B, Rago C, Velculescu V, Traverso G, Romans KE, Montgomery E, Lal A, Riggins GJ, Lengauer C, Vogelstein B, Kinzler KW: Genes expressed in human tumor endothelium. Science 289: 1197-2002, 2000.

2. Carson-Walter EB, Watkins DN, Nanda A, Vogelstein B, Kinzler KW and St Croix B: Cell surface tumor endothelial markers are conserved in mice and humans. Cancer Res 61: 6649-6655, 2001.

3. Bradley KA, Mogridge J, Mourez M, Collier RJ and Young JA: Identification of the cellular receptor for anthrax toxin. Nature 414: 225-229, 2001.

4. Bell SE, Mavila A, Salazar R, Bayless KJ, Kanagala S, Maxwell SA and Davis GE: Differential gene expression during capillary morphogenesis in 3D collagen matrices: regulated expression of genes involved in basement membrane matrix assembly, cell cycle progression, cellular differentiation and G-protein signaling. J Cell Sci 114: 2755-2773, 2001.

5. Scobie HM, Rainey GJ, Bradley KA and Young JA: Human capillary morphogenesis protein 2 functions as an anthrax toxin receptor. Proc Natl Acad Sci USA 100: 5170-5174, 2003.

6. Bradley KA, John A and Young JA: Anthrax toxin receptor proteins. Biochem Pharmacol 65: 309-314, 2003.

7. Nanda A, Carson-Walter EB, Seaman S, Barber TD, Stampfl J, Singh S, Vogelstein B, Kinzler KW and St Croix B: TEM8 interacts with the cleaved $\mathrm{C} 5$ domain of collagen alpha 3(VI). Cancer Res 64: 817-820, 2004.

8. Rmali KA, Al-Rawi MAA, Parr C, Puntis MCA and Jiang WG: Up-regulation of tumour endothelial marker- 8 by interleukin- $1 B$ and its impact in IL-1ß induced angiogenesis. Int J Mol Med 14: 75-80, 2004.

9. Beauregard KE, Collier RJ and Swanson JA: Proteolytic activation of receptor-bound anthrax protective antigen on macrophages promotes its internalization. Cell Microbiol 2: 251-258, 2000.
10. Mogridge J, Cunningham K, Lacy DB, Mourez M and Collier RJ: The lethal and edema factors of anthrax toxin bind only to oligomeric forms of the protective antigen. Proc Natl Acad Sci USA 99: 7045-7048, 2002.

11. Duesbery NS, Resau J, Webb CP, Koochekpour S, Koo HM, Leppla SH and Vande Woude GF: Suppression of ras-mediated transformation and inhibition of tumor growth and angiogenesis by anthrax lethal factor, a proteolytic inhibitor of multiple MEK pathways. Proc Natl Acad Sci USA 98: 4089-4094, 2001 .

12. Davies G, Mason MD, Martin TA, Parr C, Watkins G, Lane J, Matsumoto K, Nakamura T and Jiang WG: The HGF/SF antagonist NK4 reverses fibroblast- and HGF-induced prostate tumor growth and angiogenesis in vivo. Int J Cancer 106: 348-354, 2003.

13. Davies G, Cunnick GH, Mansel RE, Malcolm DM and Jiang WG: Levels of expression of endothelial markers specific to tumourassociated endothelial cells and their correlation with prognosis in patients with breast cancer. Clin Exp Metastasis 21: 31-37, 2004.

14. Parr C, Watkins G, Mansel RE and Jiang WG: The hepatocyte growth factor regulatory factors in human breast cancer. Clin Cancer Res 10: 202-211, 2004.

15. Jiang WG, Douglas-Jones A and Mansel RE: Expression of peroxisome-proliferator activated receptor-gamma (PPARgamma) and the PPARgamma co-activator, PGC-1 in human breast cancer correlates with clinical outcomes. Int J Cancer 106: 752-757, 2003.

16. Parr $\mathrm{C}$ and Jiang WG: Quantitative analysis of lymphangiogenic markers in human colorectal cancer. Int J Oncol 23: 533-539, 2003.

17. Jiang WG, Watkins G, Lane J, et al: Prognostic value of rho GTPases and rho guanine nucleotide dissociation inhibitors in human breast cancers. Clin Cancer Res 9: 6432-6440, 2003.

18. Rmali KA, Watkins G, Harrison G, Parr C, Puntis MCA and Jiang WG: Tumour endothelial marker-8 (TEM-8) in human colon cancer and its association with tumour progression. Eur J Surg Oncol 30: 948-953, 2004.

19. Martin TA, Parr C, Davies G, Watkins G, Lane J, Matsumoto K, Nakamura T, Mansel RE and Jiang WG: Growth and angiogenesis of human breast cancer in a nude mouse tumour model is reduced by $\mathrm{NK} 4$, a $\mathrm{HGF} / \mathrm{SF}$ antagonist. Carcinogenesis 24: 1317-1323, 2003.

20. Rice A and Quinn CM: Angiogenesis, thrombospondin, and ductal carcinoma in situ of the breast. J Clin Pathol 55: 569-574, 2002.

21. Papetti M and Herman IM: Mechanisms of normal and tumorderived angiogenesis. Am J Physiol Cell Physiol 282: C947-C970, 2002.

22. Feldman AL and Libutti SK: Progress in antiangiogenic gene therapy of cancer. Cancer 89: 1181-1194, 2000.

23. Kerbel R and Folkman J: Clinical translation of angiogenesis inhibitors. Nat Rev Cancer 2: 727-739, 2002.

24. Riche F, Dosquet C, Panis Y, Valleur P, Laisne MJ, Briard C and Wautier JL: Levels of portal and systemic blood cytokines after colectomy in patients with carcinoma or Crohn's disease. J Am Coll Surg 180: 718-724, 1995.

25. Strassmann G, Jacob CO, Fong $M$ and Bertolini DR: Mechanisms of paraneoplastic syndromes of colon-26: involvement of interleukin 6 in hypercalcemia. Cytokine 5: 463-468, 1993.

26. Jarry A, Vallette G, Cassagnau E, Moreau A, Bou-Hanna C, Lemarre P, Letessier E, Le Neel JC, Galmiche JP and Laboisse CL: Interleukin 1 and interleukin 1 beta converting enzyme (caspase 1) expression in the human colonic epithelial barrier. Caspase 1 downregulation in colon cancer. Gut 45: 246-251, 1999.

27. Bonuccelli G, Sotgia F, Frank PG, Williams TM, De Almeida CJ, Tanowitz HB, Scherer PE, Hotchkiss KA, Terman BI, Rollman B, Alileche A, Brojatsch J and Lisanti MP: Anthrax toxin receptor (ATR/TEM-8) is highly expressed in epithelial cells lining the toxin's three sites of entry (lung, skin and intestine). Am J Physiol Cell Physiol 288: C1402-C1410, 2005.

28. Liu S and Leppla SH: Cell surface tumour endothelial marker 8 cytoplasmic tail-independent anthrax toxin binding, proteolytic processing, oligomer formation, and internalization. J Biol Chem 278: 5227-5334, 2003.

29. Scobie HM and Young JAT: Interactions between anthrax toxin receptors and protective antigen. Curr Opin Microbiol 8: 106-112, 2005 . 